\title{
Environmental and economic sustainability in public contexts: the impact of hand-drying options on waste management, carbon emissions and operating costs
}

\author{
Graziano Coller $^{1} \cdot$ Marco Schiavon $^{2}$ (D) Marco Ragazzi $^{2}$
}

Received: 11 March 2020 / Accepted: 18 November 2020 / Published online: 18 January 2021

(c) The Author(s) 2021

\begin{abstract}
Due to the high density of users hosted everyday, public buildings are important producers of waste and emissions of greenhouse gases (GHGs). Public restrooms play an underrated role in waste generation and GHG emissions, especially if paper towels are used as the hand-drying method. The choice of the hand-drying method (i.e., paper towels vs. electrical hand dryers) also affects the economic balance of a public institution, involving costs for the purchase of hand-drying materials/apparatuses, energy and waste disposal. The present paper aims at evaluating the economic and environmental impact of the introduction of electrical hand dryers (alternative scenario) in place of paper towels (reference scenario) in a public building. The paper presents a solid methodology, based on a numerical experiment approach, to identify a decision criterion for establishing the economical convenience of adopting the alternative scenario in public restrooms. Key factors affecting the choice between the proposed alternatives are presented and discussed in a dedicated sensitivity analysis. From the environmental point of view, this study evaluates the impact of each scenario in terms of GHG emissions, related to multiple waste treatment options and different electric grid mixes. Based on the experimental assumptions, the method allowed concluding that the alternative scenario becomes economically convenient when the number of daily usages $(N)$ is $>57 \pm 4$. The environmental convenience of the alternative scenario is visible even at $N<10$. The method here described can be successfully used to support strategic decisions for cost optimization and environmental mitigation in institutional buildings.
\end{abstract}

Keywords Numerical experiment · Hand dryers · Paper towels · Cost analysis · Landfilling $\cdot$ Incineration

Marco Schiavon

marco.schiavon@unitn.it

Extended author information available on the last page of the article 


\section{Introduction}

The public sector has the great potential of influencing radical societal changes in many fields, including decisions leading to concrete actions toward sustainable development (AlNuaimi and Khan 2019). Compared to the private sector, the transition toward the implementation of sustainability strategies by public organizations has proceeded more slowly (Figueira et al. 2018) and has been characterized by scarcity of information on initiatives and performance (Dawkins et al. 2019). According to the United Nations Environment Programme, buildings are responsible for about 30\% of greenhouse gas (GHG) emissions at a global scale (UNEP 2009). Public buildings, especially, host everyday a high density of employees and users, which make the public sector an important energy consumer and a noticeable contributor of carbon emissions into the atmosphere. Emissions from public buildings are mainly related to the relatively high energy requirements by buildings, which account for about $25-45 \%$ of the global energy demand (Asimakopoulos et al. 2012; Jiang et al. 2014). Possible strategies to mitigate the carbon footprint of public buildings may consist in the use of secondary construction materials (Nußholz et al. 2019). However, in the case of already existing buildings, mitigation strategies should involve appropriate energy policies, such as improving the energy efficiency of buildings and choosing renewable sources of energy (Rahman 2020), but also alternative choices in the management of incoming material flows, waste generation and waste management options. Indeed, institutional buildings (i.e., buildings of public bodies, schools, university campuses, hospitals) are responsible for the generation of large amounts of waste. University campuses, especially, have been largely studied as high contributors of waste, especially food waste (if canteens are present), paper, plastics and non-recyclable waste (Abdelaal et al. 2019). Different solutions involving source-separation campaigns, the reuse of residuals and specific plans for waste management have been proposed in the past (Baldwin and Dripps 2012; Mason et al. 2004; Smyth et al. 2010). Afterward, the waste generated by institutional buildings must be transferred to waste treatment facilities, which may cause different net emissions of GHGs depending on the treatment in use (Mohareb et al. 2008). To reduce the generation of waste or prolong the life of products, in a circulareconomy perspective, a reduction, a re-arrangement or a different choice of the products entering institutional buildings should be pursued.

Public buildings are also aggregators of people, with different ages, roles, education, habits, needs and health status, which may influence the hygienic conditions of public places and the transmission of infections between employees and between users (Thapaliya et al. 2017; Zhang et al. 2018). In this sense, public restrooms play a key role, as confirmed by the recent interest of the scientific literature on hand washing and its positive influence on increasing antibiotic resistance, reducing the transmission of viruses, bacteria and fungi, both in hospital (Patrick and Van Wicklin 2012; Sabino 2016; Schultz and Spronk 2008) and in non-hospital environments (Anderson et al. 2008; Gomes et al. 2011; Park et al. 2010; Savolainen-Kopra et al. 2012). An important part of the hand washing process is hand drying. Different hand-drying alternatives are commonly available in public places: cotton towels (often arranged in rolls), paper towels and electrical hand dryers. Although the choice of the hand-drying alternative may have an influence on public hygiene (Joseph et al. 2015), hand-drying methods may have significant (though rarely visible) implications on the environment. In the last decade, the life cycle assessment (LCA) tool was implemented to evaluate the environmental impacts related to the choice of the hand-drying method. Montalbo et al. (2011) compared six different hand-drying options: standard 
electrical hand dryers, high-speed hand dryers, airblade-type hand dryers, cotton rolls, virgin paper towels, $100 \%$ recycled paper towels and cotton-roll towels. The authors showed that high-speed and airblade-type hand dryers allow for the best environmental performance compared to standard electrical hand dryers, cotton rolls and virgin/recycled paper towels, in terms of several indicators (cumulative energy demand, land occupation, ecosystem quality, human health and global warming potential). Cotton roll towels are advantageous only in terms of water consumption. Globally, the lower impacts are expected when choosing novel types of hand dryers, like high-speed hand dryers and, especially, airblade-type hand dryers (Gregory et al. 2013). Joseph et al. (2015) carried out an LCA on paper roll towels and conventional hand dryers, by analyzing four impact categories: global warming, ecosystem quality, human health and resources. The authors concluded that conventional hand dryers allow obtaining the best environmental performance in three categories out of four compared to paper roll towels. Paper roll towels would perform better only regarding the use of resources, given the higher use of electricity by conventional hand dryers during operation.

Replacing paper towels with hand dryers would also reduce the flow of waste generated by institutional buildings. Indeed, waste disposal represents a cost that public bodies must consider in their balance. In addition, if public body/institution were free to select an electric energy grid mix rich in renewable sources, they would be able to reduce their carbon footprint. However, the shift toward the adoption of hand dryers requires a case-by-case analysis, since carbon emissions are involved in the manufacturing process too (Montalbo et al. 2011), and the installation of such devices may not be economically feasible in all public restrooms. Indeed, the LCA approach might not be a suitable tool when the final results depend on a specific local context (e.g., waste management policies and electric energy production), on the variability in the utilization of a product (e.g., daily number of usages) and if specific types of costs (e.g., fixed costs) are not considered, as in Budisulistiorini (2007). Developing a method that considers these variables may lead to conclusions that are different from those that emerge from an LCA.

In the light of the previous considerations, the purpose of this paper is to propose a solid method for supporting strategic decisions in terms of cost optimization and environmental mitigation in public bodies. Specifically, the method will be here implemented to evaluate the economic and environmental impact of the introduction of a state-of-the-art and commercially available electrical hand dryer (based on the airblade-type technology) in place of paper towels in a public university campus. A reference scenario, where paper towels are used, will be compared with an alternative scenario, in which electrical hand dryers are introduced, as the preferred option that emerged from the LCAs cited. A key parameter will be defined to assess the economic sustainability of one scenario against the other.

As a matter of novelty, the manuscript proposes the application of a numerical experiment approach to evaluate both environmental and economic aspects concerning the public sector, which are strongly connected in a circular-economy perspective. By introducing the numerical experiment approach, the present paper wants to provide decision makers with a solid tool validated by a sensitivity analysis on potential factors that may affect the final results. To the authors' knowledge, a methodology including such level of detail has never been proposed to support decisions in this field. Classical LCAs, even combined with Monte Carlo analyses, include a wide range of variables to assess performance of alternative solutions according to one or few performance measures. However, the actual effect of each variable on the chosen performance measure is rarely addressed, making difficult to apply LCA results to different scenarios. The approach proposed in the present paper allows estimating how changes in the hypotheses (i.e., changes in the assumed values for 
each variable in the proposed model) affect the performance measure and thus allow to easily evaluate different scenarios.

From the environmental point of view, each scenario will be evaluated in terms of GHG emissions, following multiple waste treatment options and different electric grid mixes. In addition, in terms of carbon emissions, this paper wants to go beyond the results of the LCAs cited above (Budisulistiorini 2007; Gregory et al. 2013; Joseph et al. 2015; Montalbo et al. 2011), since the present work considers multiple scenarios for electric energy production and waste management, a variable number of users and the effect of the variability of other parameters on the final results, which can lead to different conclusions with respect to a classical LCA. Furthermore, the model allows estimating the annual cost associated with each option and evaluating the potential impact of possible changes in the cost structure of each scenario (e.g., increasing cost of energy, alternative energy mixes, increasing costs for waste treatment).

Though presented from the perspective of optimizing the economic and environmental balances of a public body in terms of the management of public restrooms, the method can be easily adapted to support decisions in other contexts where alternative processes/ technologies may be adopted in place of the existing ones. By making sustainable choices, the public sector would positively influence the whole society with the development of virtuous behaviors and the dissemination of good practices to citizens, whose active involvement is highly desirable to achieve global sustainability targets (Ling et al. 2009). Universities, especially, can be really powerful in this sense (Ahmad et al. 2012; Urbanski and Leal Filho 2015), thanks to the dynamism of students and their demonstrated interest in solving environmental issues (Steel et al. 2014).

\section{Materials and methods}

This paper employs computer simulations to model a public restroom equipped with paper towels or hand-dryers. Simulations are designed to imitate the time-evolution of a real system through an analytical model which captures the fundamental elements (defined in a set of variables) and describes the dynamics of the real system (Hartmann 1996; Law 2015). By designing an experiment on the analytical model, it is possible to learn about the behavior of the real system (Kleijnen 2015), and it is possible to compare two alternative systems under exactly the same conditions. Specifically, in this study we compare a reference (paper towels) and an alternative (hand-dryers) scenario under exactly the same usage conditions. Through sensitivity analysis, it is possible to understand which variables heavily affect the system performance (Gilbert and Troitzsch 2005).

\subsection{Definition of the reference and alternative scenarios}

This paper considers a public restroom of a university campus as a case study for the application of the methodology described in Sect. 2.2. At present, most of the public restrooms in the campus are equipped with paper towels as the hand-drying method. To compare the costs related to the installation of an electrical hand dryer (alternative scenario) with the costs related to the use of paper towels (reference scenario), it is necessary to distinguish between fixed and variable costs in both scenarios.

This paper considers a reference scenario in which the tariff system for residual waste is composed of a fixed cost, depending on the surface area of the dwelling/building, and of 
a variable cost that depends on the volume of residual waste generated by the user. This is the typical case of the province object of the present study located in northern Italy (Ragazzi et al. 2017). However, tariff systems may vary country by country and even within single countries (Pires et al. 2011). The tariff system for waste management usually covers the costs for the collection, the transportation and the disposal strategy used by the local companies or municipalities in charge for sanitation services. For large users (e.g., public bodies, schools, universities), the fixed cost is negligible compared to variable costs, and, for the specific scenario here considered, the use of paper towels does not affect the fixed cost, but only the variable cost for disposal. In addition, the fixed costs for waste disposal would be anyway charged, independently of the scenario considered. Thus, in the reference scenario, only variable costs are considered, which include the purchase of paper towels and the cost for their disposal. Fixed costs are not considered, due to the cheapness of the dispenser and because the dispenser reloading is included in the service carried out by the cleaning staff. In the alternative scenario (electrical hand dryers), this paper considers a fixed cost for the purchase of the device and a variable cost for electric energy consumption.

\subsection{Definition of the key parameter for the environmental/economic assessment}

Since the reference scenario involves only variable costs (purchase of paper towels and their disposal) and the alternative scenario considers both fixed (purchase of the hand dryer) and variable costs (electric energy consumption), the convenience of replacing paper towels with a hand dryer in a restroom can be assessed on the basis of the average daily number of usages of the restroom ( $N$, expressed as $1 / \mathrm{d})$. This independent variable can be selected as the decision criterion to establish which of the two scenarios is convenient from the economical point of view. To estimate the number of daily usages for which installing an electrical hand dryer entails the same costs compared to the use of paper towels, the following equation, comparing the daily costs of both scenarios, can be used:

$$
D F C_{h d}+N \cdot V C_{h d}=N \cdot V C_{p}
$$

where $D F C_{h d}=\frac{C_{h d, f}}{T \cdot n_{d, y}}$ is the daily fixed cost of the hand dryer [€/d], with $C_{h d, f}$ the initial fixed cost for the purchase of the hand dryer [€], $T$ the lifetime of the hand dryer [y] and $n_{d, y}$ the number of annual working days $[\mathrm{d} / \mathrm{y}] . V C_{h d}=t_{h d, u} \cdot C_{e} \cdot P$ is the variable cost of a single usage of a restroom equipped with a hand dryer [€], with $t_{h d, u}$ the time of usage of a hand dryer by a user [s/user], $C_{e}$ the average cost of electric energy [€/kWh], and $P$ the power consumption of a hand dryer [W]. $V C_{p}=n_{p, u} \cdot\left(C_{p, p}+C_{p, w d}\right)$ is the variable cost of a single usage of a restroom equipped with paper towels [€], with $n_{p, u}$ the number of paper towels used by each user [1/user], $C_{p, p}$ the cost of each paper towel [€/towel], and $C_{p, w d}$ the cost for waste disposal of each paper towel [€/towel].

By rearranging Eq. (1), $N$ can be expressed as follows:

$$
N=\frac{C_{h d_{, f}}}{T \cdot n_{d, y}\left[n_{p, u} \cdot\left(C_{p, p}+C_{p, w d}\right)-t_{h d, u} \cdot C_{e} \cdot P\right]}
$$

where $P$ must be corrected to take into account the conversions of $\mathrm{W}$ to $\mathrm{kW}$ and of seconds to hours.

The daily fixed cost of the hand dryer $D F C_{h d}$ needs to be recovered by the difference between $V C_{p}$ and $V C_{h d}$ for each single usage of the restroom. If $V C_{p}<V C_{h d}$, it is never 
convenient to install an hand dryer since the previous difference would be negative and the initial fixed cost of the hand dryer would never be recovered. This is, however, an unlikely situation since the hourly cost of energy is typically only few cents per kWh and a single usage of the hand dryer requires only few seconds. The higher the difference between $V C_{p t}$ and $V C_{h d}$, the lower is $N$. The daily fixed cost $D F C_{h d}$ heavily depends on $C_{h d, f}, T$, and $n_{d, y}$ : By keeping all the remaining parameters as equal and doubling the expected lifetime of the equipment, $T$ halves $N$ and the same holds for $n_{d, y}$.

\subsection{Simulation analysis}

Although the decision criterion presented in the previous section allows quickly identifying the best choice between the reference and the alternative scenarios, the actual result heavily depends on the hypotheses. In this section, a simulation analysis is conducted to investigate how results are affected by changes in the hypotheses and to estimate the annual cost difference between the two scenarios with changes in the number of daily usages $N$. Simulation analysis was performed with Python 3.7.5 on Linux (Ubuntu) with a Intel ${ }^{\circledR}$ Core $^{\mathrm{TM}}$ i7-5500U CPU @ $2.40 \mathrm{GHz} \times 4$. The dataset was analyzed with Microsoft Excel and Matlab version 9.5 R2018b.

\subsubsection{Estimating the annual cost difference}

As suggested by Lorscheid et al. (2012), a systematic design of experiment approach was adopted to effectively describe the simulation model behavior and the results. In the numerical experiment described in Table 1, the annual cost entailed by both scenarios (dependent variables) is computed for an increasing number of daily usages of a restroom: from 10 to

Table 1 Description of variables, factors and factor level ranges

\begin{tabular}{|c|c|c|}
\hline Variables & Factor & Factor level ranges \\
\hline \multicolumn{3}{|l|}{ Independent variables } \\
\hline Number of daily usages of a restroom & $N$ & {$[10 ; 20 ; \ldots ; 250]$} \\
\hline \multicolumn{3}{|l|}{ Control variables } \\
\hline Working days per year & $n_{d, y}$ & 250 \\
\hline \multicolumn{3}{|l|}{ Reference scenario (paper towels) } \\
\hline Number of paper towels used by each user & $n_{p, u}$ & Poisson $(\lambda=3)$ \\
\hline Cost of each paper towel purchase $(€)$ & $C_{p, p}$ & 0.005 \\
\hline Cost of each paper towel disposal $(€)$ & $C_{p, w d}$ & Uniform $\min =0.0003 \max =0.0006$ \\
\hline \multicolumn{3}{|l|}{ Alternative scenario (hand dryer) } \\
\hline Cost for the purchase of the hand dryer $(€)$ & $C_{h d, f}$ & 1000 \\
\hline Power consumption of the hand dryer (W) & $P$ & 1600 \\
\hline Lifetime of the hand dryer (y) & $T$ & 5 \\
\hline Time of usage of a hand dryer by each user (s) & $t_{h d, u}$ & Uniform $\min =14 \max =28$ \\
\hline Average cost of electric energy $(€ / \mathrm{kWh})$ & $C_{e}$ & 0.23 \\
\hline \multicolumn{3}{|l|}{ Dependent variables } \\
\hline Annual cost for the reference scenario $(€)$ & $A C_{p}$ & \\
\hline Annual cost for the alternative scenario $(€)$ & $A C_{h d}$ & \\
\hline
\end{tabular}


100 daily usages, increasing with a step of 10 . The experiment is replicated for 2000 runs and, for each value of $N$, statistics about the annual cost in the reference scenario $\left(A C_{p}\right)$ and in the alternative scenario $\left(A C_{h d}\right)$ are recorded. In other words, with this experiment the annual usage of 2000 restrooms is simulated for an increasing number of daily usages.

The number of working days $\left(n_{d, y}=250\right)$ was selected on the basis of the normal operation of a public body in the course of the year. $C_{p, p}$ was obtained by market quotations. $C_{h d, f}$ and $P$ were obtained by the manufacturer of a new model of hand dryers (Dyson 2019). $T$ coincides with the duration of the guarantee declared by the manufacturer. A Poisson distribution was chosen for $n_{p, u}$ to account for the usage of an integer number of paper towels by the users; an average number of three paper towels per user was selected. As previously mentioned, the costs for waste disposal coincide with the variable costs (depending on the volume produced) related to the user typology. The cost for waste disposal can be associated with the single paper towel used, by estimating the volume of a dry paper towel and assuming that a used paper towel is wet and its volume may double the original value, being paper towels characterized by a high porosity (>90\%) (Beuther et al. 2010). Since the volume occupied by one package of 150 new paper towels is about $1.8 \mathrm{~L}$, each waste paper towel would occupy a volume of about $0.024 \mathrm{~L}$. Based on the observation of the bills of an Italian public body with different user typologies, the costs per liter of waste were retrieved and recalculated for a single paper towel, and a uniform distribution was chosen for $C_{p, w d}$. The same type of probability distribution was adopted for $t_{h d, u}$, based on the large degree of subjectivity in the duration of each hand-drying procedure and on reasonable minimum and maximum durations. $C_{e}$ was determined by the observation of the bills of the same public body considered for the determination of $C_{p, w d}$.

\subsubsection{Sensitivity analysis}

A sensitivity analysis was performed to estimate the impact on the annual cost of both scenarios. As a first step, the impact of the number of working days was evaluated by repeating the experiment with $n_{d, y}=[50,100,150,200,250]$. The impacts of higher costs of energy $C_{e}$, higher costs of paper towels $C_{p, p}$ and disposal $C_{p, w d}$ were evaluated by repeating the experiment with a $10 \%, 20 \%, 30 \%, 40 \%$ and $50 \%$ increase of each variable. Finally, we evaluated the impact of increasing the life of the hand dryer $T$ up to 10 years.

\subsection{Carbon emissions}

\subsubsection{Reference scenario}

The reference scenario entails emissions of GHGs due to: (1) the transportation of the waste paper towels from the buildings where they are produced to the final destination of the waste; (2) the treatment of residual waste adopted in the reference region.

The effect of waste transportation on the emissions of air pollutants and GHGs has been largely investigated in the recent years, leading to the search for optimal paths and logistics (Nevrlý et al. 2018; Peri et al. 2018; Lou et al. 2020). According to (Ciuta et al. 2012), the transportation of waste can be assumed as carried out by 26-t trucks (gross weight) with a tare of $10 \mathrm{t}$. The GHGs emitted by diesel trucks are carbon dioxide $\left(\mathrm{CO}_{2}\right)$, nitrous oxide $\left(\mathrm{N}_{2} \mathrm{O}\right)$ and methane $\left(\mathrm{CH}_{4}\right)$. More specifically, $\mathrm{CO}_{2}$ emissions mostly depend on the fuel consumption, but significant contributions derive also from the consumption of lube oil and urea, if new diesel trucks are considered (EEA 2016). For instance, diesel trucks 
belonging to the Euro VI emission standard (European Commission 2011) are equipped with an SCR system for the abatement of nitrogen oxides. The $\mathrm{CO}_{2}$ emission factors for fuel consumption $\left(\mathrm{EF}_{\mathrm{CO}_{2}, f \mathrm{c}}\right)$, lube oil combustion $\left(\mathrm{EF}_{\mathrm{CO}_{2}, \mathrm{OC}}\right)$ and urea catalysis $\left(\mathrm{EF}_{\mathrm{CO}_{2}, \mathrm{UC}}\right)$ can be calculated through the methodology developed by the European Environment Agency (EEA) and, specifically, through the following equations (EEA 2016):

$$
\begin{gathered}
E F_{\mathrm{CO}_{2}, \mathrm{FC}}[\mathrm{g} / \mathrm{km}]=44.011 \cdot \frac{F C}{12.011+1.008 \cdot r_{H: C, f}+16 \cdot r_{O: C, f}} \\
E F_{\mathrm{CO}_{2}, O C}[\mathrm{~g} / \mathrm{km}]=44.011 \cdot \frac{O C}{12.011+1.008 \cdot r_{H: C, o}+16 \cdot r_{O: C, o}} \\
E F_{\mathrm{CO}_{2}, U C}[\mathrm{~g} / \mathrm{km}]=0.26 \cdot U C
\end{gathered}
$$

In the case of 26-t diesel-fueled Euro VI trucks (EEA 2016), FC, $O C$ and $U C$ are, respectively, the average kilometric fuel $(210 \mathrm{~g} / \mathrm{km})$, lube oil $(0.398 \mathrm{~g} / \mathrm{km})$ and urea $(7.35 \mathrm{~g} / \mathrm{km})$ consumptions of the vehicle. $r_{H: C, f}$ and $r_{H: C, o}$ are, respectively, the hydrogento-carbon ratios of the fuel (1.86) and of the lube oil (2.8). $r_{O: C, f}$ and $\mathrm{r}_{O: C, o}$ are, respectively, the oxygen-to-carbon ratios of the fuel and of the lube oil, both equal to 0.0.

The resulting emissions factors are $665.59,1.18$ and $1.91 \mathrm{~g} / \mathrm{km}$ for fuel, oil and urea consumption, respectively. The overall $\mathrm{CO}_{2}$ emission factor becomes $668.68 \mathrm{~g} / \mathrm{km}$. Although their emissions are lower than the total $\mathrm{CO}_{2}$ emissions in terms of mass, $\mathrm{N}_{2} \mathrm{O}$ and $\mathrm{CH}_{4}$ have relatively high global warming potentials (GWPs), respectively, 310 and 21 over a 100-year reference period (UNFCC 2019). $\mathrm{N}_{2} \mathrm{O}$ and $\mathrm{CH}_{4}$ emission factors for 26-t Euro VI diesel trucks can be estimated through the EEA methodology and result as 0.032 and $0.080 \mathrm{~g} / \mathrm{km}$, respectively (EEA 2016). In the case of $\mathrm{CH}_{4}$, the emission factor considers that the trips occur mainly on rural roads. By multiplying the $\mathrm{N}_{2} \mathrm{O}$ and $\mathrm{CH}_{4}$ emission factors by their GWPs, the respective $\mathrm{CO}_{2}$-equivalent $\left(\mathrm{CO}_{2 e q}\right)$ emission factors become 9.92 and $1.68 \mathrm{~g} / \mathrm{km}$. Thus, by adding this contributions to the overall $\mathrm{CO}_{2}$ emission factor, it is possible to calculate the total average $\mathrm{CO}_{2 e q}$ emission factor related to the transportation of waste paper towels, which results as $680.28 \mathrm{~g} / \mathrm{km}$. This value should be multiplied by the annual number of trips necessary to carry the waste paper towels away from the building where they are collected. Such step could be done by estimating the mass of each waste paper towel, which can be calculated by multiplying the volume of each waste towel $(0.024 \mathrm{~L})$ by its density, which could be assumed as equal to the water density $(1 \mathrm{~kg} / \mathrm{L})$, since it is reasonable to consider that waste paper towels are wet when collected and transferred on the trucks. The mass of each waste paper towel can then be assumed as $24 \mathrm{~g}$. Consequently, each trip would carry away a maximum of 670,000 waste paper towels. The total annual GHG emissions from waste transportation can be calculated by multiplying the $\mathrm{CO}_{2 e q}$ emission factor by the number of trips (which depends on $N$ ) and the annual mileage $(\mathrm{km})$. To simplify the presentation of the results, four distances $(L)$ from the public body to the hypothetical waste treatment facility are here considered: 50, 100, 150 and $200 \mathrm{~km}$.

Depending on the final waste treatment $(W T)$, the use of paper towels may entail additional GHG emissions that must be considered in the overall balance. Two alternative $W T$ scenarios are considered in this work for waste paper towels: landfill disposal (WT1 sub-scenario) and waste incineration (WT2 sub-scenario). In addition to biogenic $\mathrm{CO}_{2}$ emissions (not considered in the overall balance), WT1 would generate $\mathrm{CH}_{4}$ emissions due to the anaerobic biodegradation of cellulose occurring in the landfill. To model the $\mathrm{CH}_{4}$ generation from the cellulose 
biodegradation, it is necessary to estimate the content of volatile solids (VS) in cellulose and the yield of $\mathrm{CH}_{4}$ from the VS conversion. Based on (Wang et al. 2014), the net $\mathrm{CH}_{4}$ yield results as $0.34 \mathrm{Nm}^{3} / \mathrm{kg}$ of paper. The mass of a single paper towel was measured by a laboratory scale (AS120, OHAUS Corp., USA) and resulted as $1.70 \mathrm{~g}$. By assuming a reasonable value for the biogas interception rate of $75 \%$ (Levis and Barlaz 2011), considering its GWP (21), its density $\left(0.656 \mathrm{~kg} / \mathrm{m}^{3}\right)$ and considering the mass of one paper towel $(1.70 \mathrm{~g})$, the GHG emissions from the landfilling of a single paper towel account for $1.99 \mathrm{~g}$ of $\mathrm{CO}_{2 e q}$. The total $\mathrm{CO}_{2 e q}$ emissions from the WT1 sub-scenario $\left(E_{\mathrm{CO}_{2} e q, W T 1}\right)$ can be calculated by multiplying the previous value by the annual number of waste paper towels and by adding the contribution of road transport. Contrary to $W T 1, W T 2$ does not contribute to net GHG releases, since this scenario is based on the combustion of cellulose with a biogenic origin, with no production of other GHGs than biogenic $\mathrm{CO}_{2}$. Thus the $\mathrm{CO}_{2 e q}$ emissions from the WT2 sub-scenario $\left(E_{\mathrm{CO}_{2} e q, W T 2}\right)$ coincide with the emissions from road transport.

In addition to the transportation and management of waste, GHG emissions are generated also by the production process of paper towels. Montalbo et al. (2011) estimated that the production of each virgin paper towel releases $5.96 \mathrm{~g}$ of $\mathrm{CO}_{2 e q}$. Such value, multiplied by the number of paper towels used, will be summed up to the GHG emissions related to transportation and waste management.

\subsubsection{Alternative scenario}

In the case a hand dryer replaces the use of paper towels in a restroom, the GHG emissions are related to the grid mix (GM) adopted by the electric energy supplier. Two sub-scenarios are considered in this paper: the supplier produces electric energy from $100 \%$ renewable sources (GM1 sub-scenario) or from a reference mix including non-renewable sources (GM2 sub-scenario). The GHG emissions induced by $G M 1$ sub-scenario $\left(E_{C_{2} e q, G M 1}\right)$ are null, while the contribution of the GM2 sub-scenario depends on the grid mix composition. In this paper, the average grid mix of the European Union is considered, which is characterized by $29 \%$ renewable energy and by an average $C_{2 e q}$ emission factor $\left(E F_{\mathrm{CO}_{2} e q, G M 2}\right)$ of $296\left(g_{\mathrm{CO}_{2} e q} / \mathrm{KWH}\right)$ (EEA 2018). The $\mathrm{CO}_{2 e q}$ emissions caused by the $G M 2$ sub-scenario $\left(E F_{\mathrm{CO}_{2} e q, G M 2}\right)$ can be calculated by the following equation:

$$
E_{\mathrm{CO}_{2} e q, G M 2}[g / y]=\frac{E F_{\mathrm{CO}_{2} e q, G M 2} \cdot P \cdot N \cdot t_{h d, u} \cdot n_{d, y}}{1000 \frac{\mathrm{W}}{\mathrm{kW}} \cdot 3600 \frac{\mathrm{s}}{\mathrm{h}}}
$$

GHG emissions are released also by the production of the hand dryer. Such information is made available by Montalbo et al. (2011), who estimated that the manufacturing of a stateof-the-art plastic hand dryer would generate $113 \mathrm{~kg}$ of $\mathrm{CO}_{2 e q}$. Such value will be added to the GHG emissions generated by the GM2 sub-scenario and represents the only emissions produced by the $G M 1$ sub-scenario. 


\section{Results and discussion}

\subsection{Economic analysis}

The results of the simulation are summarized in Table 2 and Fig. 1. In both scenarios, as expected, the annual cost is increasing with the number of daily usages $(N)$; however, they differ as regards (1) the higher variable cost in the reference scenario and (2) the presence of fixed costs in the alternative scenario. As already mentioned in Sect. 2.2, the reference scenario involves only (higher) variable costs and the alternative scenario considers both fixed and (lower) variable costs. For this reason, the convenience of replacing paper towels with a hand dryer in a restroom depends on $N$. Since the slope of the annual cost for the reference scenario is higher than in the alternative scenario, the intersection point defines the minimum number of daily usages for which the alternative scenario has a lower annual cost $\left(N_{\text {opt }}\right)$. The results summarized in Fig. 1 show a different variability around the average annual cost for the two scenarios. Specifically, the

Table 2 Annual total cost for the reference and the alternative scenarios

\begin{tabular}{|c|c|c|c|c|c|c|}
\hline \multirow[t]{2}{*}{$N$} & \multicolumn{3}{|l|}{$A C_{p}$} & \multicolumn{3}{|l|}{$A C_{h d}$} \\
\hline & $\operatorname{Min} A C_{p}$ & $\operatorname{Avg} A C_{p}$ & $\operatorname{Max} A C_{p}$ & $\operatorname{Min} A C_{h d}$ & $\operatorname{Avg} A C_{h d}$ & $\operatorname{Max} A C_{h d}$ \\
\hline 0 & $€ 0.00$ & $€ 0.00$ & $€ 0.00$ & $€ 200.00$ & $€ 200.00$ & $€ 200.00$ \\
\hline 10 & $€ 38.80$ & $€ 40.87$ & $€ 43.13$ & $€ 205.29$ & $€ 205.37$ & $€ 205.44$ \\
\hline 20 & $€ 77.17$ & $€ 81.77$ & $€ 85.28$ & $€ 210.62$ & $€ 210.73$ & $€ 210.83$ \\
\hline 30 & $€ 117.31$ & $€ 122.63$ & $€ 128.35$ & $€ 215.98$ & $€ 216.10$ & $€ 216.22$ \\
\hline 40 & $€ 156.44$ & $€ 163.53$ & $€ 169.75$ & $€ 221.35$ & $€ 221.47$ & $€ 221.61$ \\
\hline 50 & $€ 196.08$ & $€ 204.38$ & $€ 212.26$ & $€ 226.67$ & $€ 226.83$ & $€ 226.99$ \\
\hline 60 & $€ 235.57$ & $€ 245.27$ & $€ 254.39$ & $€ 232.01$ & $€ 232.20$ & $€ 232.38$ \\
\hline 70 & $€ 275.25$ & $€ 286.18$ & $€ 297.81$ & $€ 237.38$ & $€ 237.57$ & $€ 237.74$ \\
\hline 80 & $€ 315.01$ & $€ 327.04$ & $€ 339.29$ & $€ 242.75$ & $€ 242.93$ & $€ 243.13$ \\
\hline 90 & $€ 354.53$ & $€ 367.90$ & $€ 381.05$ & $€ 248.11$ & $€ 248.30$ & $€ 248.50$ \\
\hline 100 & $€ 394.29$ & $€ 408.86$ & $€ 423.20$ & $€ 253.46$ & $€ 253.67$ & $€ 253.87$ \\
\hline 110 & $€ 434.18$ & $€ 449.67$ & $€ 466.13$ & $€ 258.83$ & $€ 259.03$ & $€ 259.24$ \\
\hline 120 & $€ 473.74$ & $€ 490.64$ & $€ 507.12$ & $€ 264.16$ & $€ 264.40$ & $€ 264.64$ \\
\hline 130 & $€ 513.08$ & $€ 531.45$ & $€ 549.92$ & $€ 269.54$ & $€ 269.77$ & $€ 269.99$ \\
\hline 140 & $€ 552.15$ & $€ 572.32$ & $€ 591.28$ & $€ 274.86$ & $€ 275.13$ & $€ 275.37$ \\
\hline 150 & $€ 591.60$ & $€ 613.27$ & $€ 634.19$ & $€ 280.24$ & $€ 280.50$ & $€ 280.83$ \\
\hline 160 & $€ 631.76$ & $€ 654.05$ & $€ 677.68$ & $€ 285.61$ & $€ 285.87$ & $€ 286.12$ \\
\hline 170 & $€ 670.99$ & $€ 694.99$ & $€ 716.83$ & $€ 290.97$ & $€ 291.23$ & $€ 291.53$ \\
\hline 180 & $€ 710.29$ & $€ 735.87$ & $€ 760.55$ & $€ 296.31$ & $€ 296.60$ & $€ 296.97$ \\
\hline 190 & $€ 751.07$ & $€ 776.66$ & $€ 803.25$ & $€ 301.66$ & $€ 301.97$ & $€ 302.28$ \\
\hline 200 & $€ 791.24$ & $€ 817.68$ & $€ 843.55$ & $€ 306.98$ & $€ 307.33$ & $€ 307.66$ \\
\hline 210 & $€ 830.64$ & $€ 858.53$ & $€ 886.24$ & $€ 312.39$ & $€ 312.70$ & $€ 313.02$ \\
\hline 220 & $€ 869.58$ & $€ 899.45$ & $€ 928.41$ & $€ 317.69$ & $€ 318.07$ & $€ 318.43$ \\
\hline 230 & $€ 910.84$ & $€ 940.37$ & $€ 969.62$ & $€ 323.12$ & $€ 323.43$ & $€ 323.74$ \\
\hline 240 & $€ 948.81$ & $€ 981.21$ & $€ 1012.47$ & $€ 328.48$ & $€ 328.80$ & $€ 329.18$ \\
\hline 250 & $€ 989.36$ & $€ 1022.09$ & $€ 1055.28$ & $€ 333.78$ & $€ 334.17$ & $€ 334.48$ \\
\hline
\end{tabular}


Fig. 1 Annual costs for the reference $\left(A C_{p}\right)$ and the alternative $\left(A C_{h d}\right)$ scenarios, including the interval between minimum and maximum values

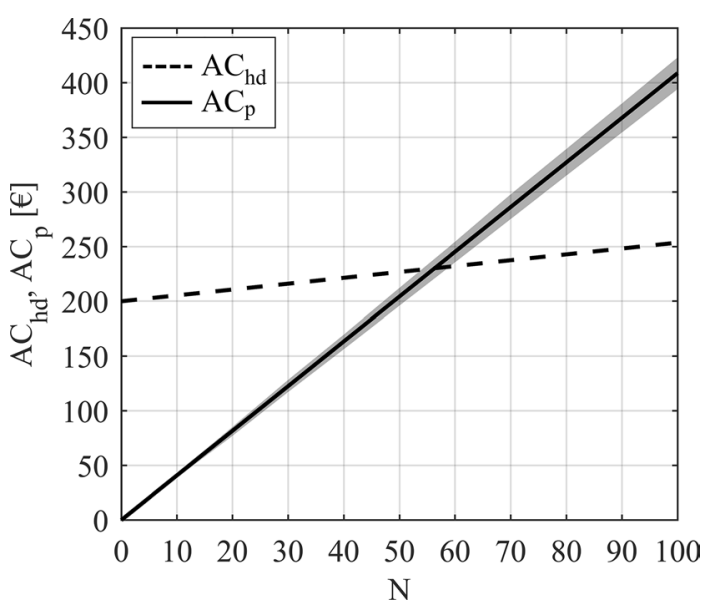

annual cost for the reference scenario $\left(A C_{p}\right)$ varies in a range of $\pm 5 \%$ around the average (the gray area in Fig. 1), while the annual cost for the alternative scenario $\left(A C_{h d}\right)$ varies in a range of $\pm 0.1 \%$ around the average. The higher variability of $A C_{p}$ depends on the higher variable cost in the reference scenario compared to the alternative scenario: From simulated data, the average annual variable cost for using the restroom once a day $(N=1)$ is $€ 4.0884$ for the reference scenario and $€ 0.5367$ for the alternative scenario. According to the decision criterion described in previous sections $N_{\text {opt }}$ is 57 .

According to the sensitivity analysis, this result slightly depends on the difference in the variable cost for the single usage of the restroom between the reference and the alternative scenario (Fig. 2a). Increasing the cost of paper towels $C_{p, p}$ and of their disposal $C_{p, w d}$ by $50 \%$ will slightly reduce the minimum number of daily usages for which the alternative scenario has a lower annual cost to $N_{\text {opt }}=54$. Increasing the cost of energy by $50 \%$ will slightly increase $N_{\text {opt }}$ to 61 . In summary, an increase in the variable cost has a relatively low impact on the annual average cost of each scenario and, according to our hypothesis, $N_{\text {opt }}$ is always in the range $N_{\text {opt }}=57 \pm 4$. A much higher impact on $N_{\text {opt }}$ is given by a change in $T$ (Fig. 2b) and in $n_{d, y}$ (Fig. 2c). Any increase in $T$ will proportionally reduce the fixed cost per year of the alternative scenario (Fig. 2b): For example, by doubling $T, A C_{h d}$ halves and so does $N_{o p t}$. It is worth to notice that this is a very likely scenario, since the hand dryer considered in the analysis has a guaranteed minimum lifespan of 5 years and there is no maintenance required. Actually, the lifetime is likely to be longer than 5 years: indeed, in case of product failures within the warranty period, the hand dryer will be repaired or replaced for free. It is also worth to notice that a change in the initial cost of the hand dryer $\left(C_{h d, f}\right)$ has a similar (but opposite) effect on $N_{o p t}$ : If $C_{h d, f}$ doubles, $A C_{h d}$ doubles and so does $N_{o p t}$. If considering now a reduction of $n_{d, y}$ from 250 to 50 days (Fig. 2c), any reduction in $n_{d, y}$ will proportionally reduce the amount of variable cost included in the annual average cost for each scenario. However, the reduction in the total annual average cost for the reference scenario is far higher. This is due to the aforementioned wide difference in the variable cost associated with each scenario, and to the annual fixed cost considered in the alternative scenario. A reduction in $n_{d, y}$ implies an increase in $N_{o p t}$. For example, reducing $n_{d, y}$ from 250 to 200 days increases $N_{\text {opt }}$ to 70; a further reduction of $n_{d, y}$ from 200 to 150 days increases $N_{o p t}$ to 94 . The reason is explained by Eq. (2): Lower working days results in 
Fig. 2 Sensitivity analysis on the annual costs for the reference $\left(A C_{p}\right)$ and alternative $\left(A C_{h d}\right)$ scenarios for higher/lower values of: a variable costs (cost of towels and their disposal, and cost of energy), b lifetime of hand dryer equipment and $\mathbf{c}$ number of working days per year
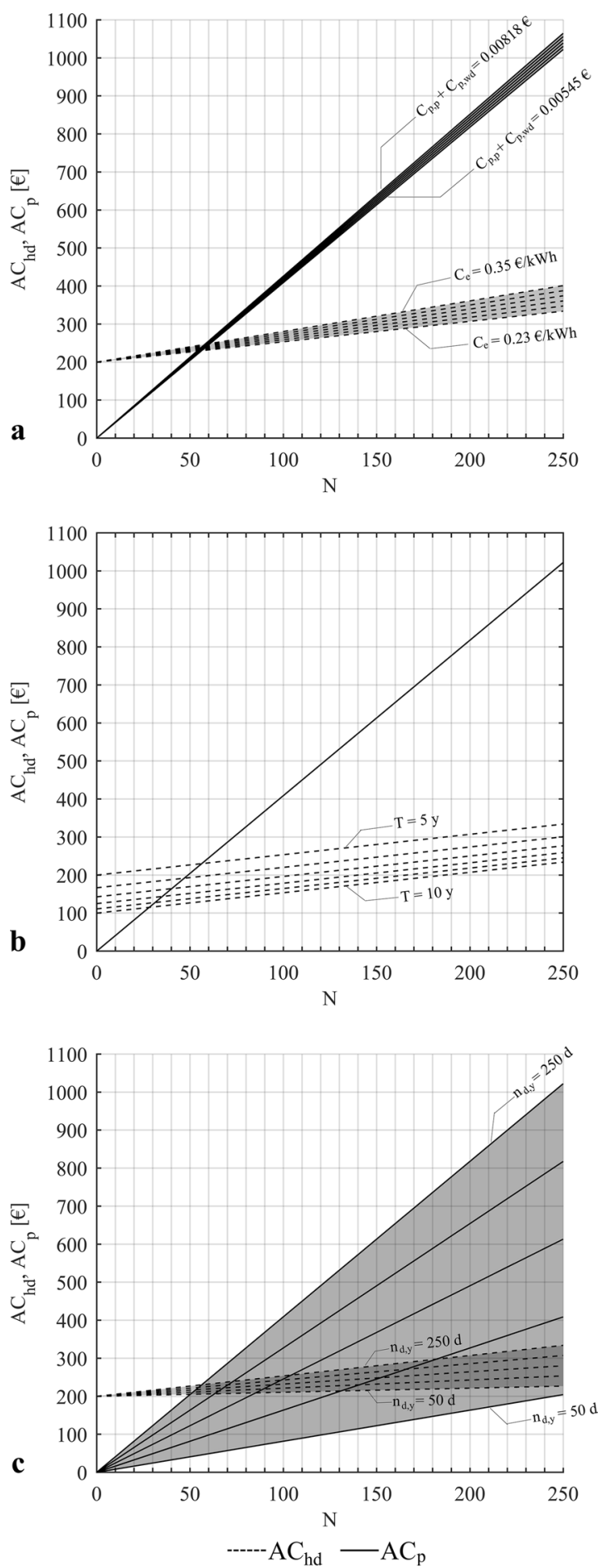
higher daily fixed costs; thus, a higher number of daily usages is needed to cover the cost differential.

\subsection{GHG emissions}

Table 3 reports the annual $\mathrm{CO}_{2 e q}$ emissions generated by the two scenarios and related sub-scenarios as a function of $N$. The results were calculated by considering the mean values of $t_{h d, u}(21 \mathrm{~s})$ and $n_{p, u}(3)$ resulting from Table 1 , and by adopting the same values reported in Table 1 regarding the remaining fixed parameters that are needed for the emission calculation (i.e., $n_{d, y}=250, P=1600 \mathrm{~W}$ and $T=5 \mathrm{y}$ ). Since the reference sub-scenarios (WT1 and WT2) consider the transportation of waste, the annual $\mathrm{CO}_{2 e q}$ emissions are expressed also as a function of $L$. On the contrary, the alternative sub-scenarios (GM1 and GM2) does not imply waste generation and, thus, waste transportation. The annual $\mathrm{CO}_{2 e q}$ emissions include the initial contribution of the hand-dryer manufacturing and, in the case of GM2, the emissions due to the consumption of electric energy generated by the average reference grid mix, which depend on $N$. Concerning the hand-dryer manufacturing, the proposed value of $113 \mathrm{~kg}$ of $\mathrm{CO}_{2 e q}$ was divided by $T$ to estimate the annual $\mathrm{CO}_{2 e q}$ emissions.

It is clear that when a hand dryer replaces the use of paper towels (sub-scenarios $G M 1$ and $G M 2$ ), $C O_{2 e q}$ emissions must be considered even when the hand dryer is not used. Indeed, Table 3 shows that GM1 and GM2 entails higher emissions than WT1 and $W T 2$ when $N<10$. By a more detailed analysis of the most precautionary comparison (GM2 vs WT2 with $L=50 \mathrm{~km}$ ), the use of the hand dryer would be disadvantageous for $N<5$. In all other cases, replacing paper towels with a hand dryer allows for evident environmental advantages, even when the grid mix used is not entirely composed by energy coming from renewable sources (GM2). If $100 \%$ renewable sources were used (GM1), 96\% (577 kg of $\mathrm{CO}_{2 e q}$ ) and 95\% (427 kg of $\mathrm{CO}_{2 e q}$ ) emission savings would be achievable with $N=100$ when compared to the $W T 1$ and WT2 sub-scenarios, respectively.

Table 3 Annual $\mathrm{CO}_{2 e q}$ emissions (expressed as $\mathrm{kg}$ ) related to the reference (WT1 and WT2) and alternative (GM1 and GM2) subscenarios

\begin{tabular}{|c|c|c|c|c|c|c|c|c|c|c|}
\hline \multirow[t]{2}{*}{$N$} & \multicolumn{4}{|c|}{$W T 1-\mathrm{L}(\mathrm{km})$} & \multicolumn{4}{|c|}{$W T 2-\mathrm{L}(\mathrm{km})$} & \multirow[t]{2}{*}{$G M 1$} & \multirow[t]{2}{*}{$G M 2$} \\
\hline & 50 & 100 & 150 & 200 & 50 & 100 & 150 & 200 & & \\
\hline 0 & 0 & 0 & 0 & 0 & 0 & 0 & 0 & 0 & 23 & 23 \\
\hline 10 & 60 & 60 & 61 & 61 & 45 & 45 & 46 & 46 & 23 & 30 \\
\hline 20 & 120 & 121 & 122 & 122 & 90 & 91 & 92 & 92 & 23 & 36 \\
\hline 30 & 180 & 181 & 182 & 183 & 135 & 136 & 138 & 139 & 23 & 43 \\
\hline 40 & 240 & 242 & 243 & 245 & 180 & 182 & 183 & 185 & 23 & 50 \\
\hline 50 & 300 & 302 & 304 & 306 & 225 & 227 & 229 & 231 & 23 & 57 \\
\hline 60 & 360 & 362 & 365 & 367 & 270 & 273 & 275 & 277 & 23 & 64 \\
\hline 70 & 420 & 423 & 425 & 428 & 316 & 318 & 321 & 324 & 23 & 71 \\
\hline 80 & 480 & 483 & 486 & 489 & 361 & 364 & 367 & 370 & 23 & 78 \\
\hline 90 & 540 & 543 & 547 & 550 & 406 & 409 & 413 & 416 & 23 & 85 \\
\hline 100 & 600 & 604 & 608 & 611 & 451 & 455 & 458 & 462 & 23 & 92 \\
\hline
\end{tabular}




\subsection{Economic impact of carbon emissions}

GHG emissions can be also quantified from an economic point of view, by considering, for instance, the market prices of the European Emission Trading System. Based on the daily $\mathrm{CO}_{2}$ European Emission Allowances prices (EEX 2019), a mean value of $23.51 € /$ ton of $\mathrm{CO}_{2}$ was calculated for the present year (2019). This value can be used to calculate the increase in the annual costs deriving from the emissions of GHGs concerning the case that considers the transportation and treatment of waste paper towels (WT1 and WT2 scenarios) and the case that considers the production of hand dryers and the related electric energy consumption (GM1 and GM2 scenarios). In the worst case scenario (WT1 with $\mathrm{L}=200 \mathrm{~km}$ ), the annual cost of the reference scenario slightly increases by $14.36 €$ when considering the estimated annual costs related to carbon emissions. This outcome strengthens the results of the simulation analysis, since the inclusion of the costs related to GHG emissions is equivalent to a $95 \%$ increase in $C_{p, w d}$, and has the same effect on $N_{\text {opt }}$ of an increase in the variable cost (see Fig. 2a).

\subsection{Comparison with previous studies}

As previously mentioned, airblade-type hand dryers are the preferable solution in terms of a series of environmental indicators, including global warming potential (Montalbo et al. 2011). The benefits of airblade-type hand dryers emerge intrinsically by the emission balance, which considers the GHG emissions related to the manufacturing process (Table 3). The advantages of hand dryers are even higher because of the avoided GHG emissions from waste transportation. These results are confirmed by the work of Joseph et al. (2015), which estimated that the global warming potential of hand dryers is about $60 \%$ lower than that of paper towels. The results of Joseph et al. (2015) are very close to those obtained by Gregory et al. (2013), especially concerning high-speed hand dryers (e.g., airblade-type). Budisulistiorini (2007) got to the same conclusions in terms of the environmental impacts of electrical hand dryers compared to paper towels. However, from the economic point of view, the results of the present paper cannot be compared with those of Budisulistiorini (2007): indeed, the cost analysis provided by the author is partial, i.e., the investment costs of hand dryers and the costs for waste management are not considered.

\section{Conclusions}

The present paper proposed a methodology based on a numerical experimental approach, developed to evaluate the economical and environmental convenience of replacing paper towels with electrical hand dryers in the restrooms of a university campus located in northern Italy. The results of the simulation analysis, comparing the reference case (paper towels) with the alternative case (electrical hand dryers), showed that the installation of electrical hand dryers (airblade-type) in place of paper towels in the context of an institutional buildings' restroom is worthwhile for a number of daily usages higher than 50-60. As a result of the sensitivity analysis, this threshold is heavily affected by the fixed costs incurred in the alternative scenario (i.e., hand-dryer purchase), by the hand dryer lifetime, and, especially, by the number of working days per year (i.e., the number of days in which the restroom is actually used): In other words, for public buildings with seasonal openings 
or with partial openings during the weeks, $N_{\text {opt }}$ threshold would be much higher and paper towels may be the best option. The threshold is also heavily affected by the difference between the variable costs incurred in the reference and in the alternative scenario. Overall, from an economic standpoint, hand dryers are a viable alternative to paper towels only for restrooms with an influx higher than the $N_{\text {opt }}$ threshold in terms of daily usages.

From an environmental standpoint, hand dryers are the preferred alternative to paper towels (see Table 3). Since waste is not produced when using hand dryers instead of paper towels, the emissions from waste transportation are null in the alternative scenario. This implies lower GHG emissions, which are only due to the share of fossil fuels in the grid mix. The maximum benefits are achievable when the electric energy employed comes from renewable sources. In the present case, for $N>50-60$, the alternative scenario is ameliorative from both the economic and environmental points of view.

The estimated annual costs and GHG emissions are here referred to a single restroom. Replicating the substitution of paper towels with hand dryers in many public restrooms, multiplies the economic and environmental advantages described in the present paper. However, the results refer to airblade-type hand dryers; alternative types of hand dryers (i.e., traditional electric) may not be as efficient and may require a higher energy consumption. This would reduce the variable cost differential between the reference and the alternative scenario and thus increase $N_{\text {opt }}$.

The methodology presented in this paper improves upon the classical LCA approach: The results of LCA applications on hand-drying methods are based on a high rate of utilization of each method and do not always consider fixed costs in the economic assessment. The present methodology considers the effect of a variable number of users (representing the typical case of a public building), allows performing a detailed economic analysis, and includes the effect of the variability of other factors in a sensitivity analysis, supporting the choice of one method rather than another, from both economic and environmental points of view.

Though referred to a specific case study, the present methodology can be easily applied to other geographical contexts with different waste treatment alternatives and grid mixes. In addition, numerical experiments can be applied to support decisions in other fields, whenever alternative processes/technologies are available.

Funding Open access funding provided by Università degli Studi di Trento within the CRUI-CARE Agreement. The authors did not receive any specific funding for this research.

Availability of data and materials Simulation results were generated by a custom code on Python 3.7.5 and are available upon request.

Code availability Custom code on Python 3.7.5 available upon request.

\section{Compliance with ethical standards}

Conflict of interest The authors declare no conflicts of interests/competing interests.

Open Access This article is licensed under a Creative Commons Attribution 4.0 International License, which permits use, sharing, adaptation, distribution and reproduction in any medium or format, as long as you give appropriate credit to the original author(s) and the source, provide a link to the Creative Commons licence, and indicate if changes were made. The images or other third party material in this article are included in the article's Creative Commons licence, unless indicated otherwise in a credit line to the material. If material is not included in the article's Creative Commons licence and your intended use is not 
permitted by statutory regulation or exceeds the permitted use, you will need to obtain permission directly from the copyright holder. To view a copy of this licence, visit http://creativecommons.org/licenses/by/4.0/.

\section{References}

Abdelaal, A. H., McKay, G., \& Mackey, H. R. (2019). Food waste from a university campus in the Middle East: Drivers, composition, and resource recovery potential. Waste Management, 98, 14-20.

Ahmad, W., Soskolne, C. L., \& Ahmed, T. (2012). Strategic thinking on sustainability: Challenges and sectoral roles. Environment, Development and Sustainability, 14, 67-83.

AlNuaimi, B. K., \& Khan, M. (2019). Public-sector green procurement in the United Arab Emirates: Innovation capability and commitment to change. Journal of Cleaner Production, 233, 482-489.

Anderson, J. L., Warren, C. A., Perez, E., Louis, R. I., Phillips, S., Wheeler, J., et al. (2008). Gender and ethnic differences in hand hygiene practices among college students. American Journal of Infection Control, 36, 361-368.

Asimakopoulos, D. A., Santamouris, M., Farrou, I., Laskari, M., Saliari, M., Zanis, G., et al. (2012). Modelling the energy demand projection of the building sector in Greece in the 21st century. Energy and Buildings, 49, 488-498.

Baldwin, E., \& Dripps, W. (2012). Spatial characterization and analysis of the campus residential waste stream at a small private liberal arts institution. Resources, Conservation and Recycling, 65, 107-115.

Beuther, P. D., Veith, M. W., \& Zwick, K. J. (2010). Characterization of absorbent flow rate in towel and tissue. Journal of Engineered Fibers and Fabrics, 5, 1-7.

Budisulistiorini, S. H. (2007). Life cycle assessment of paper towel and electric dryer as hand drying method in the university of Melbourne. Teknik, 28, 132-141.

Ciuta, S., Schiavon, M., Chistè, A., Ragazzi, M., Rada, E. C., Tubino, M., et al. (2012). Role of feedstock transport in the balance of primary pm emissions in two case-studies: RMSW incineration vs. sintering plant. UPB Scientific Bulletin Series D: Mechanical Engineering, 74, 211-218.

Dawkins, E., André, K., Axelsson, K., Benoist, L., Gerger Swartling, Å., \& Persson, Å. (2019). Advancing sustainable consumption at the local government level: A literature review. Journal of Cleaner Production, 231, 1450-1462.

Dyson Ltd. (2019). Dyson Airblade V Hand Dryer. Accessed 15 January 2020, from https://www.dyson .com/hand-dryers/dyson-airblade-v-overview.html.

EEA. (2016). EMEP/EEA air pollutant emission inventory guidebook 2019. European environment agency. Accessed 19 January 2020, from https://www.eea.europa.eu/publications/emep-eea-guidebook-2019.

EEA. (2018). Overview of electricity production and use in Europe. https://www.eea.europa.eu/data-andmaps/indicators/overview-of-the-electricity-production-2/assessment-4. Accessed 16 January 2020.

EEX. (2019). European emission allowances. Accessed 19 January 2020, from https://www.eex.com/en/ market-data/environmental-markets/spot-market/european-emission-allowances.

European Commission (2011). Commission Regulation (EU) No 582/2011.

Figueira, I., Domingues, A. R., Caeiro, S., Painho, M., Antunes, P., Santos, R., et al. (2018). Sustainability policies and practices in public sector organisations: The case of the Portuguese central public administration. Journal of Cleaner Production, 202, 616-630.

Gilbert, G. N., \& Troitzsch, K. G. (2005). Simulation for the social scientist (2nd ed.). London: Open University Press.

Gomes, A., Fraga, S., \& Ramos, E. (2011). Hand washing and diarrhoea in adolescents. Journal of Public Health, 19, 401-407.

Gregory, J. R., Montalbo, T. M., \& Kirchain, R. E. (2013). Analyzing uncertainty in a comparative life cycle assessment of hand drying systems. International Journal of Life Cycle Assessment, 18, 1605-1617.

Hartmann, S. (1996). The World as a Process. In R. Hegselmann, U. Mueller, \& K. G. Troitzsch (Eds.), Modelling and simulation in the social sciences from the philosophy of science point of view (pp. 77-100). Netherlands: Springer.

Jiang, P., Chen, Y., Dong, W., \& Huang, B. (2014). Promoting low carbon sustainability through benchmarking the energy performance in public buildings in China. Urban Climate, 10, 92-104.

Joseph, T., Baah, K., Jahanfar, A., \& Dubey, B. (2015). A comparative life cycle assessment of conventional hand dryer and roll paper towel as hand drying methods. Science of the Total Environonment, 515-516, $109-117$.

Kleijnen, J. P. C. (2015). Design and analysis of simulation experiments (2nd ed.). Berlin: Springer.

Law, A. M. (2015). Simulation modeling and analysis (5th ed.). London: McGraw-Hill Education. 
Levis, J. W., \& Barlaz, M. A. (2011). Is Biodegradability a desirable attribute for discarded solid waste? Perspectives from a national landfill greenhouse gas inventory model. Environmental Science and Technology, 45, 5470-5476.

Ling, C. L., Hanna, K., \& Dale, A. (2009). A template for integrated community sustainability planning. Environmental Management, 44, 228-242.

Lorscheid, I., Heine, B.-O., \& Meyer, M. (2012). Opening the 'black box' of simulations: Increased transparency and effective communication through the systematic design of experiments. Computational and Mathematical Organization Theory, 18, 22-62.

Lou, C. X., Shuai, J., Luo, L., \& Li, H. (2020). Optimal transportation planning of classified domestic garbage based on map distance. Journal of Environmental Management, 254, 109781.

Mason, I. G., Oberender, A., \& Brooking, A. K. (2004). Source separation and potential re-use of resource residuals at a university campus. Resources, Conservation and Recycling, 40, 155-172.

Mohareb, A. K., Warith, M. A., \& Diaz, R. (2008). Modelling greenhouse gas emissions for municipal solid waste management strategies in Ottawa, Ontario, Canada. Resources, Conservation and Recycling, 52, 1241-1251.

Montalbo, T., Gregory, J., \& Kirchain, R. (2011). Life cycle assessment of hand drying systems. Massachusetts Institute of Technology: Materials Systems Laboratory.

Nevrlý, V., Šomplák, R., Gregor, J., Pavlas, M., \& Klemeš, J. J. (2018). Impact assessment of pollutants from waste-related operations as a feature of holistic logistic tool. Journal of Environmental Management, 220, 77-86.

Nußholz, J. L. K., Nygaard Rasmussen, F., \& Milios, L. (2019). Circular building materials: Carbon saving potential and the role of business model innovation and public policy. Resources, Conservation and Recycling, 141, 308-316.

Park, J.-H., Cheong, H.-K., Son, D.-Y., Kim, S.-U., \& Ha, C.-M. (2010). Perceptions and behaviors related to hand hygiene for the prevention of H1N1 influenza transmission among Korean university students during the peak pandemic period. BMC Infectious Diseases. https://doi.org/10.1186/1471-2334-10-222.

Patrick, M., \& Van Wicklin, S. A. (2012). Implementing AORN recommended practices for hand hygiene. AORN Journal, 95, 492-507.

Peri, G., Ferrante, P., La Gennusa, M., Pianello, C., \& Rizzo, G. (2018). Greening MSW management systems by saving footprint: The contribution of the waste transportation. Journal of Environmental Management, 219, 74-83.

Pires, A., Martinho, G., \& Chang, N.-B. (2011). Solid waste management in European countries: A review of systems analysis techniques. Journal of Environmental Management, 92, 1033-1050.

Ragazzi, M., Fedrizzi, S., Rada, E. C., Ionescu, G., Ciudin, R., \& Cioca, L. I. (2017). Experiencing urban mining in an Italian municipality towards a circular economy vision. Energy Procedia, 119, 192-200.

Rahman, M. M. (2020). Environmental degradation: The role of electricity consumption, economic growth and globalisation. Journal of Environmental Management, 708, 134653.

Sabino, R. (2016). Hospital environment. In C. Viegas, A. C. Pinheiro, R. Sabino, S. Viegas, J. Brandão, \& C. Veríssimo (Eds.), Environmental mycology in public health (pp. 193-210). Amsterdam: Elsevier.

Savolainen-Kopra, C., Haapakoski, J., Peltola, P. A., Ziegler, T., Korpela, T., Anttila, P., et al. (2012). Hand washing with soap and water together with behavioural recommendations prevents infections in common work environment: An open cluster-randomized trial. Trials. https://doi. org/10.1186/1745-6215-13-10.

Schultz, M. J., \& Spronk, P. E. (2008). The effects of hand-washing, restrictive antibiotic use and SDD on morbidity. In P. H. J. van der Voort \& H. K. F. van Saene (Eds.), Selective digestive tract decontamination in intensive care medicine: a practical guide to controlling infection (pp. 99-110). Milan: Springer.

Smyth, D. P., Fredeen, A. L., \& Booth, A. L. (2010). Reducing solid waste in higher education: The first step towards 'greening' a university campus. Resources, Conservation and Recycling, 54, 1007-1016.

Steel, B. S., Pierce, J. C., Warner, R. L., \& Lovrich, N. P. (2014). Environmental value considerations in public attitudes about alternative energy development in Oregon and Washington. Environmental Management, 55, 634-645.

Thapaliya, D., Taha, M., Dalman, M. R., Kadariya, J., \& Smith, T. C. (2017). Environmental contamination with Staphylococcus aureus at a large, Midwestern university campus. Science of the Total Environment, 599-600, 1363-1368.

UNEP. (2009). Buildings and climate change summary for decision-makers. UNEP DTIE sustainable consumption and production branch. Accessed 17 February 2020, from https://europa.eu/capacity4dev/ unep/documents/buildings-and-climate-change-summary-decision-makers.

UNFCC. (2019). Global warming potentials. Accessed 16 February 2020, from https://unfccc.int/process/ transparency-and-reporting/greenhouse-gas-data/greenhouse-gas-data-unfccc/global-warming-poten tials. 
Urbanski, M., \& Leal Filho, W. (2015). Measuring sustainability at universities by means of the sustainability tracking, assessment and rating system (STARS): Early findings from STARS data. Environment, Development and Sustainability, 17, 209-220.

Wang, B., Nges, I. A., Nistor, M., \& Liu, J. (2014). Determination of methane yield of cellulose using different experimental setups. Water Science and Technology, 70, 599-604.

Zhang, N., Huang, H., Su, B., Ma, X., \& Li, Y. (2018). A human behavior integrated hierarchical model of airborne disease transmission in a large city. Building and Environment, 127, 211-220.

Publisher's Note Springer Nature remains neutral with regard to jurisdictional claims in published maps and institutional affiliations.

\section{Affiliations}

\section{Graziano Coller ${ }^{1} \cdot$ Marco Schiavon $^{2}$ (D) Marco Ragazzi² $^{2}$}

Graziano Coller

graziano.coller@unitn.it

Marco Ragazzi

marco.ragazzi@unitn.it

1 Department of Economics and Management, University of Trento, Via Inama 5, 38122 Trento, Italy

2 Department of Civil, Environmental and Mechanical Engineering, University of Trento, Via Mesiano 77, 38123 Trento, Italy 